\title{
Jockeying for Position: The construction of masculine identities 1 .
}

In recent years it has become increasingly difficult for men to ignore the issue of their gendered status. Gone, it seems, are the days when men sat comfortably as the unmarked sex. Instead the 'masculine condition' has been put under the spotlight in a barrage of television and radio programmes, newspaper and magazine articles. The same is also true within the social sciences with a steady stream of new titles about men and masculinity emerging from a range of theoretical perspectives, including sociology (e.g. Connell, 1995; Hearn, 1987), ethnography (e.g. Cornwall and Lindisfarne, 1994; Mac an Ghaill, 1994) and feminist theory (e.g. Segal, 1990 - see Edley and Wetherell, 1995 for a critical review).

A number of arguments have been put forward to explain this proliferation of interest. Most centre upon the notion that it reflects some kind of contemporary crisis in defining masculinity (Kimmel, 1987). The available historical evidence (Hall, 1992; Hoch, 1979; Mangan and Walvin, 1987; Segal, 1990; Roper and Tosh, 1991) suggests, however, that any such crisis is the latest in a long line of such episodes. The meanings given to masculinity are not static or unitary and change is not the perogative of new postmodern times. The analyses emerging in cultural studies and social history have emphasised the fiercely contested nature of masculinity over time, the multiple possibilities for masculine self-definition in different periods and the struggle which occurs to establish certain constructions as hegemonic and dominant (see, most notably, the perspective developed by Carrigan et al. 1985; Connell, 1987; 1995).

In his analysis of the representations of men found in popular culture, Jonathan Rutherford (1988) was one of the first to suggest that current conceptions of masculinity exemplify a tension between two dominant images or subject positions: 'retributive man' and 'new man'. Retributive man represents a more traditional form of masculine identity. He is the (major) breadwinner of the family and the principal source of authority 
within the home: tough, competitive and emotionally inarticulate. In contrast, new man represents the ideal partner for the modern, liberated, heterosexual woman ("Germaine Greer's soul mate" - The Independent on Sunday, 14th April 1991). He is a softer, more sensitive and caring individual, who also avoids sexist language, changes nappies and loves to shop all day for his own clothes.

The emergence of the 'new man' as a cultural frame of reference has been linked to changes in other social and economic practices such as the 'feminisation' of the work-force and the shift from manufacturing (such as coal-mining and ship-building) to service industries organised around computer-based technologies. Rutherford argues that the context in which traditional forms of masculine identity made sense is rapidly disappearing. A further (overdetermining) factor is the feminist movement and its critique of men and male psychology. Irrespective of whether it has made men angry, guilty, defensive or determined to change, feminism has had a tremendous impact upon the ways in which, particularly middle-class, men view their own lives (see also Christian, 1994; Segal, 1990).

From a social psychological point of view one of the difficulties with these notions of the 'new man' and 'retributive man' is their global sweep and lack of grounding in the actual interactional and discursive practices of men in mundane life. Cultural ideals tend to become confused with types of personality and seen in a categorical and privatised way so that it becomes reasonable to ask whether any particular man is best described as a 'new' or 'retributive' type. One of the aims of this paper is to take heed of recent analyses of broad cultural changes in definitions of masculinity (including debates about whether these represent something new in the balance of power in gender relations or merely a modernising of patriarchical practices) but to maintain an empirical focus on discursive practices. We wish to examine the ways in which men become constitutedas men within ordinary talk and how men (as competent members of cultural communities) use debates within those communities as central resources in their self-constructions. In this paper, our particular focus is on a group for whom debates about the 'new man' appear 
particularly apposite - middle-class young men in the final years of school - and the 'cults' of masculinity found in their community.

We will be assuming in this analysis a broadly social constructionist perspective on self and identity as that term has been used in recent years in social psychology (Gergen, 1985; Wetherell and Maybin, 1996). Instead of reproducing a traditional Western view of people as unique, selfcontained motivational and cognitive universes (Geertz, 1973), we will be treating selves as being accomplished in the course of social interactions; reconstructed from moment to moment within specific discursive and rhetorical contexts, and distributed across social contexts (see Edley, 1993; Harre, 1993; Henriques et al, 1984; Potter and Wetherell, 1987; Shotter and Gergen, 1989; Widdicombe and Wooffitt, 1995 for further examples of work within the tradition Edwards and Potter, 1992, usefully designate as 'discursive psychology').

It has become commonplace in recent years to divide discursive studies within social psychology into two camps (Burr, 1995; Parker, 1992; Widdicombe and Wooffitt, 1995), drawing a distinction between 'topdown' and 'bottom-up' approaches. 'Top-down' forms of discursive psychology focus on issues of power, ideological practice and social process (e.g. Wetherell and Potter, 1992; Parker, 1992; Hollway, 1984) and typically draw upon analytical concepts of discursive regimes, interpretative repertoires, cultural narratives and subject positions in order to highlight the ways in which people are spoken through or by discourses.

We need to recognise that the narrator, rather than being the sovereign origin of what gets said, is instead a kind of passage through which those discourses (or narratives) presently in circulation speak. (Freeman, 1993, p. 198)

In contrast, 'bottom-up' approaches draw more enthusiastically on the work of Sacks than Foucault and locate their concerns within the traditions of ethnomethodology and conversation analysis (e.g. Antaki, 1988, Edwards and Potter, 1992, Edwards, 1996, Widdicombe and Wooffitt, 1995). Attention is focused upon the action orientation (Heritage, 1984) of 
people's discourse; that is, upon the kinds of things accomplished through talk, such as accusations, criticisms and mitigations. There is more emphasis here on 'sticking to the data', that is, on being able to demonstrate that an analyst's concern, for instance with gender, is also a participants' concern within the interaction and present as a trace in the talk before it can be imported into the analysis.

In addition, while 'top-down' researchers study the way people are positioned by and effected through discourse, 'bottom-up' researchers emphasise people's activities, highlighting the remarkable subtleness and sophistication of ordinary people's talk and its designed features. Another key difference concerns the supposed role and status of the analyst. In studying the operations of ideology, members of the 'top-down' camp see the analyst as occupying a somewhat advantageous position. Put somewhat crudely, the analyst sees things that ordinary folk do not. By comparison, the status of the analyst implied within the 'bottom-up' camp is much less elevated. Indeed, not only do these researchers see the analyst as having something to learn from ordinary people's talk, but they also insist that analysis is only possible because the analyst and those analysed share the same discursive competencies.

Similarly, as Edwards (1996) has noted, there is an important related distinction between those for whom social constructionism is primarily an ontological position and those who take it as primarily an epistemological claim. The former place most stress on the social constitution of mind, taking mind and the social as (more or less) real and conventionally describable entities. While the latter focus more on the constructed and relative nature of talk and are more interested in studying how versions of events, including analysts' versions, are built up and worked to become factual, persuasive and presented as 'just the way the world is'.

While the distinction between 'top-down' and 'bottom-up' has been useful for clarifying key theoretical and methodological issues it is also, in our view, time to move on. Our broad aim is to build forms of discursive psychology which draw more eclectically on both styles of work and which study the ways in which people are simultaneously the master, and 
the slave, of discourse (Barthes, 1982). In line with the arguments of Billig (1991) and Sampson (1993), the contradictions need to be embraced rather than trying (in vain) for resolution. The two approaches are most usefully understood as reflecting two sides of a central paradox: people are simultaneously the products and the producers of discourse. We are both constrained and enabled by language; the "truth", here, is paradoxical. So attempts to dissolve or resolve these contradictions are a mistake because, as Billig (1991) points out, such attempts "will be less convincing than accounts which express the paradox itself" (p. 9).

To summarize, we want in this paper to examine the (re)construction of masculine identities via this double focus. That is, we want to look at, not only the ways in which men are positioned by a ready-made or historically given set of discourses or interpretative repertoires, but also at the ways in which these cultural resources are manipulated and exploited within particular rhetorical or micro-political contexts. Our aim is to put some flesh on broader claims about the changing nature of masculinity in popular culture and show how these are instantiated as local and contextual phenomena.

\section{Analytical Materials}

The material for this analysis comes primarily from a series of taperecorded and transcribed interviews conducted during 1992 and 1993 (Wetherell and Edley, 1993). They consist of a set of discussions held over a nine month period with small groups of 17-18 year old boys attending the sixth form of a UK based, single sex, independent school. All of the participants were volunteers whose anonymity, along with that of their peers and teachers, is guaranteed primarily through the provision of pseudonyms. In all there were three groups of three boys who, along with the interviewer (NE), met at regular intervals on the school premises during school hours (although, for reasons which we will discuss shortly, we will be focusing on material from just two of the discussions groups - B and C). The discussions themselves were loosely structured around a range of different topics, including sexuality and relationships, images of 
men in popular culture and feminism and social change. However, at all times the aim of the interviewer was to create an informal atmosphere in which, to a large extent, the participants themselves directed the flow of conversation. All of the extracts presented below come with a "postscript" identifying the precise group and session from which the material is taken. For example, "(B5)" represents an extract taken from the fifth meeting of Group B (see Appendix for a brief note on transcription notation).

\section{Formulating the Research Questions}

In addition to the transcribed material, analysis was guided by a reflexive ethnography (Atkinson, 1989) conducted by Nigel Edley which involved periods of observation within the sixth form of the school and discussions with staff and pupils. This ethnographic work led to the identification of divisions within friendship groups in the sixth form as a major participant concern connected with formulations of masculinity within the school. A consensus view held by staff and pupils was that the sixth form was organised into a number of different and somewhat antagonistic groups. At the heart of the sixth form common room stood the largest, and in many ways the most powerful group in the school. Made up largely of the school's rugby players, these young men dominated school life in a number of different ways. A key part of their domination was physical. During break-times, for instance, they would literally take over the common room with their boisterous games, forcing everyone else out on to the peripheries. Moreover, these games, like that of rugby, served to underline their ability to give and take physical punishment; a core aspect of the traditional definition of masculinity and a constant reminder of the threat posed to anyone wishing to challenge their dominant position.

Significantly, the status of the rugby lads was further supported and sustained by certain formal structures within the school. For example, its 'honours' system recognized sporting achievement in a much more explicit way compared to academic success, with each member of the school's rugby (and cricket) team being entitled to wear a distinctively coloured 
blazer, which clearly elevated him above the black-blazered majority. Furthermore, the rugby players were heavily over-represented in terms of positions of authority within the student body - such as head boy, house captains and prefects. These positions provided their encumbents, not only with institutional power, but also with the kudos of having been personally selected by the school's head teachers.

The divisions within the sixth form common room became an important topic in the tape-recorded interviews initiated both by the interviewer and introduced on many occasions as a point of reference by the participants themselves. For the two groups (B and C) analysed here, it was particularly predominant since the participants in these discussion groups came not from the (self-defined) 'sporty or hard lads' but from a friendship group within the common room who defined themselves as "diametrically opposed" to the rugby players. The antipathy this friendship group felt towards the 'hard lads' appeared to play a central organising role in this group's day-to-day school life. "We hate their guts" declared one, speaking on behalf of his friends. "They're a complete bunch of wankers" remarked another in a later interview. Not only did these boys see themselves as different to the rugby players, but they also saw themselves as superior. "You need to realise" one explained "that we are not the hard lads and we probably enjoy being slightly different and doing different things".

The analysis that follows is based on a close reading of all the transcribed material from Discussion Groups B and C concerned with the groupings within the sixth form and reports one main theme in these discussions. We focus on the interviewees' efforts to construct alternative, counterhegemonic identities for themselves. For if it is in anyone's interests to exploit the critical or rhetorical opportunities provided by the subject position of the 'new man', it is surely in the interests of those in the common room overtly opposed to the 'hard lads'. 


\section{Defined by Difference: Constructing Self and Other}

Post-structuralist theorists have pointed out that all concepts are relational; defined, that is, by contrast with other concepts (Derrida, 1973). The concept of masculinity is, of course, no exception to this rule, being constructed most clearly as a difference from femininity. Significantly, Edward Said (1978) has suggested that people often gain a sense of their own identities through a related process of differentiation. In other words, we define ourselves negatively, in terms of being different from somebody else. Those who are not 'us' define who 'we' are. Certainly this claim would appear to be borne out by the comment above, where a non-rugby player represents his group precisely in these terms. However, the point is that here the identity of the Other is male, not female. As Connell (1995) has argued (and see also Segal, 1990) masculinity is best constructed in the plural rather than the singular, noting that these plural masculinities are intimately linked, one to another. Consider Extract One, for example.

1.

AARON: With our group I think it'd be fair to say, it would be the easiest group to join. Whereas to be in the rugby group would be hard (.) I mean if you want to or not (.) I mean I wouldn't but you'd have to (.) it's all very chauvanistic and male and all that stuff (.) to get in there you'd have to like be 'ard and get kicked about a bit (C 3)

Here we see Aaron clearly differentiating his friendship group from the rugby lads. Unlike his group, he says, you have to be a particular kind of individual to join the rugby players. "To get in there you'd have to be hard and get kicked about a bit", he says, "it's all very chauvanistic and male". The most significant feature of this construction is, of course, the final comment. For in constructing an equation of machismo with maleness Aaron is left with few options for positioning himself. Indeed, it would appear that in order to differentiate himself (and his friends) from the rugby players, he must relinquish a masculine identity all together. Significantly, in an earlier interview with Group B, there was clear evidence of precisely this strategy of differentiation. 
2.

NEIL: [...] whereas they'd probably see themselves as men and I'd probably see myself as a person rather than a man (.) well I am a man (.) I don't know

(B 1)

Here we can see Neil abandoning a masculine identity in the process of differentiating himself from the rugby players. "They see themselves as men", he says, whereas "I'd probably see myself as a person rather than a man". However, as we can also see, Neil immediately tries to reclaim a masculine identity for himself. "Well I am a man (.) I don't know". He appears to be caught in the grip of a powerful ideological dilemma (Billig et al, 1988). It is as if he wants to say: "I am a man, but not that type of man", except that the strict equation of machismo with manliness seems to rule out any such alternative. Yet, almost paradoxically, a sign of just such an alternative is contained within Aaron's discourse in Extract 1. For in using the adjective "chauvanistic", he could be seen as aligning himself with the feminist movement and its critique of macho masculinity. A similar kind of reading can be made of Extracts 3 and 4 below.

3.

NATHAN: And I do think that they do define masculinity by (.) which women they've been out with and shagged [making inverted commas sign]

(B 1)

4.

PHIL: Yeah (.) er I think if you had to erm (.) if you were listening to election speeches by all these groups of people the rugby sporting group would be you know (.) "We'll turn the common room into a football pitch and we'll have free beer" and like this and "It'll be really great and you'll have a really (.) and there'll be girlies (.) beer and girlies and rugby" and things like that you know (C 2) 
In these extracts the talk seems to be simply about the rugby players. And yet, if we look more closely, we can see the two speakers are simultaneously constructing their own identities. When Nathan uses the word "shagged", for example, he is careful to signal that this is not part of his vocabulary. Rather, like Phil's talk of "beer and girlies and rugby", it is constructed as referencing a lexicon which belongs to another type of man: the macho man. So, if the macho man is Other, where does this leave Nathan and Phil? In producing a critical discourse of the rugby players as male chauvanists, presumably one possibility would be to assume an alternative subject position like the 'new man' identified by Rutherford and others as currently available in popular culture.

For Aaron and his friends, the identity or subject position of the 'new man' could represent an important cultural resource, allowing them not only to distinguish themselves from the rugby players, but also to challenge the basis of their power. For within its terms, the rugby players become objects of derision rather than admiration; their macho games appearing stupid rather than cool, pathetic rather than hard. As we noted, however, the 'new man' does not go uncontested. In attempts to re-establish the normality of macho masculinity, and to have it reinstated as the right and proper way of being a man, alternative forms of masculinity become labelled deviant. 'New men' are not real men at all, they are "sissies", "poofs" and "wimps".

Within the interviews, the non-rugby players dealt with these kinds of potentially damaging re-presentations in a number of different ways. One of the boldest strategies occured during a discussion about fighting and male violence, which saw Neil accepting one of these "discredited" identities. "I've been a bit of a pacifist wimp" he said. In Extract 5 the interviewer (Nigel) follows up this remark.

5.

NIGEL: Okay there was something you said Neil that just interested me there (.) you said erm that you described yourself as a erm pacifist (.) wimp (1.0) do you really see youself as [a] wimp. 
NEIL: Oh yeah (1.0) yeah because (2.0) I've got this theory that em (1.0) I'm ss(.) I don't do anything (.) I'm scared of getting hurt (.) I mean I suppose everybody is but er (1.0) yeah I do I mean er if a wimp (1.0) a wimp (2.0) if a wimp's somebody who'll back down from a fight or won't get into them (.) and is seen as being (.) you know (.) physically less able (.) then that's fine (.) I'm happy with that

KEITH: There's nothing wrong with being a wimp is there? (laughter) It stops you getting beaten up [laughing] (B 4)

There are, of course, historical precedents to this kind of strategy (Hunter, 1992). Many gay men, for example, refer to themselves as "queers", whilst the term "nigger" has recently been appropriated by certain sections of the black community. The effect is (supposed to be) disarming, because the whole object of a taunt is that it is unwelcome and hurtful. However, in many ways it represents a high risk strategy insofar as people can interpret them as accepting the whole weight of negative baggage which accompanies such labels. To some extent, Neil and Keith can be seen to be orientating to this concern. For whilst Neil, at least, embraces the identity of a wimp, he does so on the explicit proviso that the concept is defined in such a way that it might be acceptable to many, if not all, men. Even so, only three turns later Neil produces another version of himself one which sees him disowning the identity of the wimp.

6.

NEIL: Actually (.) just thinking like that I think you know a wimp is probably not just physically (.) I think people who are mentally weak as well (.) and I don't think I'm mentally weak as in I can't stand up for myself verbally or you know (.) or perhaps a wimp's someone's who's timid and shy as well (.) but yeah I mean if you ask somebody they'd probably say some Emo Phillips [a stand-up comedian who adopts the personna of a weak, ineffectual man] type character (.) someone you know like that [...] I mean we probably strike a balance between you know (.) talking about what they talk (.) talking about what (.) you know probably we'd class as the other 
people's talk because I mean they talk about all sorts of you know (.) there's this lad Kelner who'll talk about nuclear physics or something you know spiel on for hours and the other lot'll talk about how did United do at the weekend and did you see that gorgeous bit of tot or whatever (1.0) so I think we probably (.) you know we talk about some interesting things including some bits in the middle. (KS B 4)

Neil's new definition of the wimp is centred around a distinction between two kinds of strength (or weakness); namely, physical and mental. Under this new definition, the wimp appear as someone who has neither of these attributes. Neil, on the other hand, lays claim to mental toughness. In other words, the wimp is constructed as another kind of Other, a second reference point from which Neil can differentiate himself. Like Jason and the Argonauts, Neil and his friends can be seen carefully navigating a course for themselves between the Scylla of the macho man and the Charybdis of the wimp. Not as obsessed about sport as the hard lads, nor about nuclear physics as the wimps, Neil and his friends are betwixt and between, a diluted mixture of both.

There would appear to be an element of complicity here between Neil and the hard lads (see Connell, 1995 for a fuller discussion of this notion). He may not have the physical strength of the rugby players, but at least he has got some kind of strength. In a sense, therefore, the credibility of Neil's identity is dependent here upon some level of proximity to or correspondence with those of the macho men. In the following extract we see Neil drawing upon the very same distinction between physical and mental strength in order to undermine the position of the rugby lads.

7.

NEIL: I mean you could probably draw a list up (.) of what the qualities that make you eligible for [the hard group] (.) I mean (.) you've probably got to be attractive (.) handsome (.) good at sport (.) physically strong and I'd probably say mentally weak to go along with them [laughter] but I mean you've got to be (.) probably pretty sheepish follow the herd to do that whereas I doubt if one of them 
would stand out and say something against their whole group whereas one of us lot wouldn't think twice about it

(B 1)

Here we see Neil constructing a kind of identi-kit portrait of the typical rugby player. At first the list seems pretty complimentary, but then comes the sting in the tail. For all their bulging biceps, the rugby players are said to lack mental strength. They are portrayed as unthinking conformists, incapable, or even scared, perhaps, of doing their own thing. In this way a categorical difference is established between the identity of the speaker (and his friends) and the hard lads. No longer are they pale versions of the same thing. Instead a rough kind of equality is struck: both groups are represented as being strong, albeit in different ways. This attempt to undermine the position of the rugby players is extened further in extracts 8 and 9 where, yet again, the same conceptual distinction is used. In both instances the boys are in the process of talking about the role of violence in men's lives.

8.

KEITH: No but I think it's because like for some of us it would take a bit of working up before (.) but for them they're always ready to give some (.) I suppose your right (.) but it's not so much that if they did start anything it's just that it's always the outwards show of muscle

NEIL: It's like a show of weakness I think (.) that you have to resort to that (.) so that's probably what stops me having a go at one of them

NATHAN: I don't like to use physical violence not just because sometimes I might like lose or whatever but like sometimes I have in the past like (.) lost control and I don't like doing that (B 2)

9.

NEIL: There's a few people (.) a few you know perhaps in September I've thought you know "I've about had enough of this (.) I'm gonna go and smack this kid" but I (.) you know I've only (.) I've 
only started (.) I've only had a brief fight with one person since September you know I (.) I've got quite a lot of self control because I could probably name about 10 people who I've you know been extremely tempted or less than that (.) but you know there's a few people I really would like to go and er smack because they really do get on my nerves and I don't (.) I don't bother them but they bother me (NIGEL: Hm m) and er (.) I think sometimes it'll come to a point where I may have to do that (.) but it's not something that I'd be proud of (.) I mean I'm more proud of the fact that I've been restrained I think than letting go

(B 4)

As with extract 7, a key difference between the participants and the rugby players is said to be the latters' lack of mental toughness (in this case "control" or strength of character). Moreover, the hard lads' outward displays of physical aggression are constructed by Neil as being evidence of their lack of character. Unlike him, they lack the mental discipline or sophistication to deal with difficult situations in civilised ways. As soon as the rugby players are provoked they have to resort to violence. In contrast, Neil, Nathan and, arguably, Keith pride themselves upon being able to "restrain" themselves.

Yet perhaps the most significant feature of these extracts is the way in which each speaker manages to construct himself as capable of physical aggression. It is not that they cannot engage in displays of macho violence, it is just that they all have the self discipline to control such outbursts. Keith argues that he and his friends just require "a bit of working up" before they resort to violence. So while they claim to have slightly longer fuses, the implication is that that when they "go off", the result is just as spectacular. Similarly, Neil portrays himself as teetering on the brink of "smacking" some of the hard lads. It is not that he cannot do it, it is just that he does not want to. Nathan's account is also constructed upon a supposed distaste of physical violence. Yet, in many ways, his argument is even stronger. For unlike the others, he claims to have actually lost control of himself in the past. The main virtue of this account is that, in claiming a history of physical violence, Nathan heads off 
the assumption that his current pacifism hides a cowardly streak. However, of all these tales of self containment, probably the most colourful appears in extract 10 below from Discussion Group B.

10.

AARON: I'm fairly quick thinking on my feet so I can usually talk my way (.) talk myself out of doing anything more than anything else.

PAUL: You tend to size up the situation you just think (.) there's no point in getting into a fight you're gonna lose is there?

AARON: No (.) I mean (.) a lot of situations [inaudible] the first option that really presents is hit them and then the rest of them are self control measures (1.0) think quick on your feet (.) talk your way out of this (1.0) so I've got (.) I have to talk my way out of it so that I'm not seen as the loser (NIGEL: Right) I don't mind a draw but I can't be a loser so I have to talk my way out of it so I look good to myself (.) otherwise I get very aggressive.

NIGEL: Okay, so erm (.) there has to be some sort of showdown which can be verbal?

AARON: Yeah (.) I mean (.) as I say I'm a fairly quick talker (.) so I'm (.) with regard to other people I think

NIGEL: Can you think of an episode where that's been the case?

AARON: Not recently (.) not really (.) erm (.) well (.) perhaps with Tommy Ladham on the football field (1.0) he's a (.) he's very aggressive but not very intelligent (NIGEL: Hm m) I'm not saying I'm intelligent (2.0) so there was a situation (.) well it was a dodgy tackle (.) I mean both of us just went for the ball as hard as possible and there wasn't really (.) and he got all on his high horse (.) "If you do that again I'll take your shins away" (.) and erm (.) you know (.) the aggression bar went straight up on me (.) I was thinking to myself and erm (.) I mean I totally outworded the lad (.) because I'm quick at thinking on my feet (1.0) I can just quickly reel off something(.) blah blah blah blah and he just (.) walked off (C 7) 
Reminiscent of a scene from the film Cerano de Bergerac, Aaron describes a battle between braun and brains. And just as in the story, the hero defeats his enemy with a mixture of guile and wit. It is a victory of mind over muscle, of mental control over violent physical action.

Looking back over the last three extracts it is possible to detect a certain 'turning of the tables' taking place. In differentiating themselves from the rugby players, Aaron, Neil and the other members of the friendship group have not really portrayed themselves as departing from the traditional definition of masculinity at all. Indeed, they have represented themselves as out-doing the rugby players at pretty much their own game. If anything, this is even clearer in the final two extracts (11 and 12) which both appeared in the context of more general critical discussions about the behaviour of "macho" masculinity.

11.

KEITH: But they're always seeking to try and prove it NATHAN: They define themselves (.) I think much more as a group than as individuals

NEIL: I think (.) what Keith says they think that they have to prove it whereas other people

KEITH: They would just be more relaxed (.) you know (NATHAN: And as a group) they don't have to dive on somebody to prove they're hard or

(B 1)

12.

PAUL: If you go to Anytown and let's say and you go out with a group of lads saying you're going out on the pull (.) they're doing it from a (.) as Phil said the more hard macho image (.) but they get (.) well(.) nowhere (.) because they're just going for a gawp PHIL: It's just bragging (.) I mean like we said (.) didn't we say before that people who tend to talk about having sex or sexual conquests all the time tend to have had (AARON: Very little) very little experience whatsoever and those who tend to keep it quiet have. Erm (.) and I think the same goes for this sort of situation (.) 
if you say "I'm going out on the pull" you can always guarantee that they're not gonna get it (AARON: Yeah) you know (.) they're not gonna pull.

(C 5)

Here the speakers appear to be drawing upon a lay version of psychoanalytic theory to achieve their rhetorical aims. They suggest that the rugby players' conspicuous displays of macho behaviour - the play fighting and the tales of sexual conquest - are not to be taken seriously. Indeed, they argue that such behaviour is evidence of their shortcomings as men. The real hard men are those who do not need to dive on each other in an attempt to prove their masculinity. Likewise, the ones who are really getting the sex are not those who stand up and shout about it in the middle of the common room. They are the ones who are sitting quietly on the sidelines, secure in their own sense of gendered self.

\section{Discussion and Conclusions}

In this paper we have looked at the construction of masculine identities within a specific cultural and institutional setting. As anticipated, it did not reveal the existence of stable or consistent selves, but a good deal of variation in the ways in which the participants talked about their own gender identities. However, as Marx might have said, whilst men make their own identities, they do not make them just as they please. They make them under circumstances directly encountered, given and transmitted from the past (c.f. Marx, 1951). Here, those circumstances are the institutional practices of the school, which both privilege and, to a certain extent, produce a particular version of masculinity. The hard lads or sporty boys are its main representatives (both symbolically and literally). As a consequence, school life for them is relatively straight-forward. For the remainder, however, life is much more difficult. They are the ones who are most alienated by the dominant cultural order.

It is in the very nature of the phenomenology of power that those at the centre who have it experience its workings the 
least. [T]o have power is to find no resistance to the realisation of one's desires... It is those without power who find at every turn resistances to the realization of their desires. (Shotter, 1993. pg. 40 - see also Billig, 1991, Chp 4).

But, we have also tried to demonstrate the active and highly creative rhetorical work involved in formulating identity under these circumstances. Although broad sweep analyses of cultural types such as the 'new man' and the 'retributive man' are useful, what these analyses do not convey is the lived texture of the rhetoric and its instantiation in everyday discursive practices. When we look in this way, strategies appear complex, contradictory and multiple and, in terms of ideological practice, messy.

On the one hand, the interviewees built a critique of a form of masculinity, a form which certainly requires critical examination. In Connell's (1987; 1995) terminology, the dominant position of the rugby players, the hegemonic group, was challenged by a subordinated or marginalised group - a cultural struggle was thus vividly reproduced in talk. Yet, in this case, there was also complicity. New identities were built in dialogue with the identities which were to be challenged and superceded. The development of an adequate feminist politics around masculinity we suggest will depend on taking these patterns in the mobilisation of meaning into account, both in terms of the content of the identities being formulated here by young white middle-class men and the process of discursive change which seems entailed. While for an adequate discursive psychology of masculinity, it seems necessary to be able to work closely with text, to examine its design, as well as interpreting the place of those designs in terms of more global social contexts. 


\section{Acknowledgements}

The research reported in this paper was funded by the Economic and Social Research Council (Grant No. R000233129), the Open University and the Nottingham Trent University. Our most important debt, however, is to the men who took part in this study. Needless to say, without their kindness, co-operation and openness and their willingness to submit their discourse to critical commentary such work as this would never get done. 


\section{Appendix}

\section{Transcription Notation}

The following transcription notation represents a simplified version of that

developed by Gail Jefferson (see Atkinson and Heritage (1984) for a more comprehensive account).

(.) Short pause of less than 1 second.

(1.0) Timed pause (in seconds).

[...] Material deliberately omitted.

[text] Clarificatory information.

text Word(s) emphasized. 


\section{References}

Antaki, C. (1988) (ed.) Analysing Everyday Explanation: A Casebook of Methods. London: Sage.

Atkinson, P. (1989) The Ethnographic Imagination. London: Routledge.

Atkinson, J.M. and J.C. Heritage (1984) (eds) Structures of Social Action:

Studies in Conversation Analysis. Cambridge: Cambridge

University Press.

Barthes, R. (1982) Inaugural lecture, College de France. In S. Sontag (ed.) A Barthes Reader. London: Jonathan Cape.

Billig, M. (1991) Ideology and Opinions: Sudies in Rhetorical Psychology. London: Sage.

Billig, M., S. Condor, D. Edwards, M. Gane, D. Middleton and A. Radley (1988) Ideological Dilemmas: A Social Psychology of Everyday Thinking. London: Sage.

Burr, V. (1995) An Introduction to Social Constructionism. London: Routledge.

Carrigan, T., R.W. Connell and J. Lee (1985), Towards a new sociology of masculinity. Theory and Society, 14, 551-604.

Christian, H. (1994) The Making of Anti-Sexist Men. London: Routledge.

Connell, R.W. (1987) Gender and Power. Cambridge: Polity

Connell, R.W. (1995) Masculinities. Cambridge: Polity.

Cornwall, A. and N. Lindisfarne (eds.) (1994) Dislocating Masculinity: Comparative Ethnographies. London: Routledge. 
Derrida, J. (1973) Speech and Phenomena and Other Essays on Husserl's Theory of Signs. Evanston: Northwestern University Press.

Edley, N. (1993) 'Prince Charles - Our Flexible Friend: accounting for variations in constructions of identity' Text. 13 (3) 397-422.

Edley, N. and M. Wetherell (1995) Men in Perspective: Practice, Power and Identity. Hemel Hempstead: Prentice Hall/Harvester Wheatsheaf.

Edwards, D. (1996) Discourse and Cognition. London: Sage.

Edwards, D. and J. Potter (1992) Discursive Psychology. London: Sage.

Freeman, M. (1993) Rewriting the Self: History, Memory, Narrative London: Routledge.

Geertz, C. (1973) The Interpretation of Cultures. New York: Basic Books.

Gergen, K. (1985) 'The social constructionist movement in modern psychology', American Psychologist, Vol. 40, pp. 266-75.

Hall, C. (1992) White, Male and Middle Class: Explorations in Feminism and History Cambridge: Polity Press.

Harre, R. (1993) Social Being. (2nd Ed.) Oxford: Blackwell.

Hearn, J. (1987) The Gender of Oppression: Men, Masculinity and the Critique of Marxism. Brighton: Harvester Wheatsheaf.

Henriques, J., W. Hollway, C. Urwin, C. Venn and V. Walkerdine (1984) Changing the Subject: Psychology, social regulation and subjectivity. London: Methuen. 
Heritage, J. (1984) Garfinkel and Ethnomethodology Cambridge: Polity.

Hoch, P. (1979) White Hero, Black Beast: Racism, Sexism and the Mask of Masculinity London: Pluto Press.

Hollway, W. (1984), 'Gender difference and the production of subjectivity'. In Henriques et al. (eds) Changing the Subject:

Psychology, social regulation and subjectivity. London: Methuen.

Hunter, A. (1992) 'Same door. Different closet'. Feminism and Psychology, 2, 367-387.

Kimmel, M.S. (ed.) (1987) Changing Men: New directions in research on men and masculinity Newbury Park: Sage.

Mac an Ghaill, M. (1994) The Making of Men: Masculinities, Sexualities and Schooling. Buckingham: Open University Press.

Mangan, J.A. and J. Walvin (eds) (1987) Manliness and Morality: Middle class masculinity in Britain and America 1800-1940 Manchester: Manchester University Press.

Marx, K. (1951) Marx-Engels, Selected Works. London: Lawrence and Wishart.

Roper, M. and J. Tosh (1991) (eds) Manful Assertions: Masculinities in Britain since 1800 London: Routledge.

Rutherford, J. (1988) 'Who's That Man?' in R. Chapman and J. Rutherford (eds.) Male Order: Unwrapping Masculinity London: Lawrence and Wishart.

Parker, I. (1992) Discourse Dynamics: Critical Analysis for Social and Individual Psychology. London: Routledge. 
Potter, J. and M. Wetherell (1987) Discourse and Social Psychology: Beyond attitudes and behaviour London: Sage.

Sampson, E.E. (1993) Celebrating the Other: A Dialogic Account of Human Nature. Hemel Hempstead: Harvester Wheatsheaf.

Said, E. (1978) Orientalism. Harmondsworth: Penguin.

Segal, L. (1990) Slow Motion: Changing men, changing masculinities. London: Virago.

Shotter, J. (1993) The Cultural Politics of Everyday Life. Milton Keynes: Open University Press.

Shotter, J. and K.J. Gergen (1989) (eds) Texts of Identity. London: Sage.

Wetherell, M. and Maybin, J. (1996) The distributed self. In R. Stevens (ed) Understanding the Self. London: Sage

Wetherell, M. and J. Potter (1989) Narrative characters and accounting for violence. In J. Shotter and K.J. Gergen (eds) Texts of Identity London: Sage.

Wetherell, M. and J. Potter (1992) Mapping the Language of Racism: Discourse and the legitimation of exploitation Harvester Wheatsheaf.

Wetherell, M. and N. Edley (1993) 'Men and Masculinity: A sociopsychological analysis of discourse and gender identity'. ESRC grant No. R000233129.

Widdicombe, S. and R. Wooffitt (1995) The Language of Youth SubCultures: Social Identity in Action. Hemel Hempstead: Harvester Wheatsheaf. 